\title{
Early Versus Delayed Reversal of Covering Stoma after Low Anterior Resection for Colorectal Carcinoma
}

\author{
Taha Mohamed Fayed, Ayman Mohammed AbdulMohaymen, and Eid Rizk El Gammal \\ Surgical Oncology Unit, Faculty of Medicine, Al-Azhar University, Cairo, Egypt \\ Corresponding author: Taha Mohamed Fayed, Email: tahafayed40@ gmail.com
}

\begin{abstract}
Background: A defunctioning stoma is used primarily to protect the anastomosis and prevent pelvic sepsis after bowel surgery.

Aim of the work: This study was aimed to compare early stoma closure with conventional stoma closure following defunctioning diversion stoma surgery with respect to the frequency of complications, health-related quality of life (QOL), and length of hospitalization (LOH).

Patients and Methods: This study was designed as a prospective parallel-arm randomized controlled trial. 40 patients who underwent temporary stoma following colorectal cancer surgery were enrolled in this study. The rate of complications (medical and surgical) following early (20 patients) and conventional (20 patients) stoma closure was assessed. Health-related QOL and LOH were also measured.

Results: Forty patients were included, with 20 cases in each group. Postoperative complications including wound dehiscence ( $15 \%$ vs. $15 \% ; P=1.00)$, wound infection $(40 \%$ vs. $5 \% ; P=0.023)$, intra-abdominal collection ( $15 \%$ vs. $30 \% ; P=0.449)$, anastomotic leak ( $15 \%$ vs. $30 \% ; P=0.449)$ were comparable. The length of hospital stays and overall mortality and morbidity were similar across the two groups. There was a significant reduction in the cost towards stoma care in the early stoma closure group. Furthermore, Patients in the early stoma closure group also had a significantly better QOL.

Conclusion: Early stoma closure does not carry an increased risk of postoperative complications, reduces cost towards stoma care, and leads to better a QOL.
\end{abstract}

Keywords: Colorectal carcinoma, Stoma, Early closure, Delayed closure.

\section{Introduction}

A defunctioning stoma is used primarily to protect the anastomosis and prevent pelvic sepsis after bowel surgery ${ }^{[1-4]}$. A Cochrane review reported that temporary ileostomy is associated with fewer anastomotic leakages ${ }^{[5]}$. Matthiesen et $\boldsymbol{a l}$. reported that a defunctioning stoma reduces the need for urgent reoperation ${ }^{[6]}$. Stoma closure is usually performed after 8-12 weeks. However, quality of life (QoL) is affected due to stoma-related complications during this time

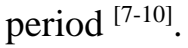

Early closure of temporary stoma might reduce both stoma-related morbidity and patient discomfort. Alves et al. reported that reversal of temporary stoma 8-10 days after surgery is feasible; however, with higher wound complications ${ }^{[15]}$. Other studies have also found that outcome did not differ significantly between early and late stoma closure regarding morbidity and mortality ${ }^{[16-18]}$.

Restoration of intestinal continuity is generally associated with a low mortality ${ }^{[19]}$. However, stoma reversal may cause major complications ranging from $0 \%$ to $9 \%$ and minor complications varying from $4 \%$ to $30 \%$, requiring reoperation [16].

The reports on early versus conventional stoma closure are conflicting ${ }^{[20.22]}$. Hence aim of this study was to compare early versus late closure of stoma in cases of low anterior resection for colorectal carcinoma as regarding hospital stay, quality of life, and post-operative complication.

\section{Patients and Methods}

This randomized controlled trial included a total of 40 patients who underwent temporary stoma following colorectal cancer surgery attending at Department of Surgical Oncology, Bab-Elshaarya University Hospital. Approval of the ethical committee and a written informed consent from all the subjects were obtained. This study was conducted between September 2017 and September 2018.

The patients (40) were divided into two groups, 20 each; early and late (conventional). The rate of complications (medical and surgical) following early (before three months) and late 
(after three months) temporary ileostomy closure was assessed. Health-related QOL and $\mathrm{LOH}$ were also measured.

Screening for and inclusion of participants was made after the index surgery low anterior resection for colorectal cancer with creation of a temporary ileostomy. Follow-up of patients was at the time of closure, 3,6 , and 12 months after index surgery.

\section{Inclusion criteria:}

Patients eligible for enrolment into this study were $>15$ and $<70$ years of age and had all received surgical treatment (low anterior resection of the rectum or colon resection) for colorectal cancer with the construction of a temporary ileostomy.

\section{Exclusion criteria:}

Patients were excluded if they had advanced disease, advanced age, or obstructed tumor.

\section{Randomization}

Participants were randomized to either early (before three months) or delayed (after three months) reversal of the temporary ileostomy. Inclusion and randomization were carried out shortly after the CT scan.

\section{Surgical technique}

The surgical technique was the standard procedure, and the closure of the stoma was carried out with either a suture-only or staplingonly technique. The information was registered regarding the surgical intervention: ASA score, whether the anastomosis was hand-sutured or stapled, blood loss, duration of surgery and anesthetic method.

Outcomes

The primary end-point of the study was frequency of complications 0-12 months after initial surgery. All complications within 12 months postoperatively were registered. The stoma related complications were registered retrospectively by inspection of patient during hospital stay and in the outpatient clinics. The secondary end-points of the study were the cost and quality of life.

\section{Statistical analysis}

Recorded data were analyzed using the statistical package for social sciences, version 20.0 (SPSS Inc., Chicago, Illinois, USA). Quantitative data were expressed as mean \pm standard deviation (SD). Qualitative data was expressed as frequency and percentage. Independent-samples t-test of significance was used when comparing between two means. Chisquare $\left(\mathrm{x}^{2}\right)$ test of significance was used in order to compare proportions between two qualitative parameters. The confidence interval was set to $95 \%$ and the margin of error accepted was set to $5 \%$. So, the P-value $\leq 0.05$ was considered significant.

\section{Results}

We included 20 cases in each group. The demographic data of these patients were summarized in Table 1. There was no difference between the study groups regarding the comorbidities.

Table 1. Comparison between groups according to demographic data.

\begin{tabular}{|c|c|c|c|c|}
\hline Demographic Data & $\begin{array}{l}\text { Group I: Early closure } \\
(\mathbf{N}=\mathbf{2 0})\end{array}$ & $\begin{array}{l}\text { Group II: Delayed } \\
\text { closure }(\mathrm{N}=20)\end{array}$ & $t / x 2 \#$ & p-value \\
\hline $\begin{array}{l}\text { Age (years) } \\
\text { Mean } \pm \text { SD } \\
\text { Range }\end{array}$ & $\begin{array}{c}49.45 \pm 12.98 \\
26-66\end{array}$ & $\begin{array}{c}48.35 \pm 9.29 \\
30-68\end{array}$ & 0.095 & 0.760 \\
\hline $\begin{array}{l}\text { Gender } \\
\text { Female } \\
\text { Male }\end{array}$ & $\begin{array}{l}8(40.0 \%) \\
12(60.0 \%)\end{array}$ & $\begin{array}{c}9(45.0 \%) \\
11(55.0 \%)\end{array}$ & $0.102 \#$ & 0.749 \\
\hline $\begin{array}{l}\text { BMI }\left(\mathrm{kg} / \mathrm{m}^{2}\right) \\
\text { Mean } \pm \text { SD } \\
\text { Range }\end{array}$ & $\begin{array}{l}24 \pm 3.2 \\
17-32\end{array}$ & $\begin{array}{l}23 \pm 4.5 \\
19-35\end{array}$ & 0.095 & 0.760 \\
\hline
\end{tabular}

$t$-Independent Sample t-test; \# $x^{2}$ : Chi-square test

p-value $>0.05 \mathrm{NS}$

Among the included patients of the earlyclosure group, 14 patients had the tumor in the rectum, while six patients had the tumor in the sigmoid colon. On the other hand, the delayedclosure group contained 13 patients with rectal cancer and 7 patients with sigmoid colon cancer.

Regarding the distance of the lower border of the tumor from the anal verge, the early-closure group contained six patients with lower border 
distant by $5-9 \mathrm{~cm}$, nine patients with lower border distant by $10-20 \mathrm{~cm}$, and five patient distant by $>20 \mathrm{~cm}$. On the other hand, the delayed-closure group contained seven patients with lower border distant by $5-9 \mathrm{~cm}, 10$ patients with lower border distant by $10-20 \mathrm{~cm}$, and three patient distant by $>20 \mathrm{~cm}$. The stages of the tumor were summarized in Table 2.

Table 2. Comparison between groups according to stage.

\begin{tabular}{|c|c|c|c|c|}
\hline Stage & $\begin{array}{c}\text { Group I: Early closure } \\
\qquad(\mathbf{N}=\mathbf{2 0})\end{array}$ & $\begin{array}{l}\text { Group II: Delayed } \\
\text { closure }(\mathrm{N}=20)\end{array}$ & $\mathbf{X} 2$ & p-value \\
\hline $\operatorname{t} 1 \mathrm{n} 2 \mathrm{~m} 0$ & $0(0.0 \%)$ & $1(5.0 \%)$ & \multirow{7}{*}{3.817} & \multirow{7}{*}{0.701} \\
\hline t2n0m0 & $9(45.0 \%)$ & $7(35.0 \%)$ & & \\
\hline t2n1m0 & $3(15.0 \%)$ & $4(20.0 \%)$ & & \\
\hline $\mathrm{t} 2 \mathrm{n} 2 \mathrm{~m} 0$ & $6(30.0 \%)$ & $5(25.0 \%)$ & & \\
\hline t3n1m0 & $0(0.0 \%)$ & $1(5.0 \%)$ & & \\
\hline $\mathrm{t} 3 \mathrm{n} 2 \mathrm{~m} 0$ & $1(5.0 \%)$ & $2(10.0 \%)$ & & \\
\hline $\mathrm{t} 3 \mathrm{n} 3 \mathrm{~m} 0$ & $1(5.0 \%)$ & $0(0.0 \%)$ & & \\
\hline
\end{tabular}

Regarding the time of closure, the stomas of the early-closure group were closed after $2.65 \pm$ 0.81 weeks, while the stomas of the delayedclosure group were closed after 24.00 \pm 7.34 weeks. There was a significant difference between the two groups (P-value < 0.001).

Having the complications, there was a significant difference between the two study groups regarding the urinary tract infection, and wound infection with higher wound infection in the early-closure group and higher rate of UTI in the delayed-closure group. Other complication showed no significant differences with $\mathrm{P}>0.05$. The mean number of complications was 1.32 in the intervention group compared with 2.74 in the control group. with a ratio for intervention versus control of 0.48 (95\% CI 0.32-0.57), $\mathrm{P}<0.002$.

Having the stoma related complications, there were significant differences between study groups regarding skin irritationand leakage outside appliance bag. Other Stoma related complications showed no statistically significant differences between the two groups (Table 3).

Table 3. comparison between the two groups according to the stoma related complications.

\begin{tabular}{|l|c|c|c|c|}
\hline $\begin{array}{l}\text { Type of stoma related } \\
\text { complications }\end{array}$ & $\begin{array}{c}\text { Group I: Early } \\
\text { closure (N=20) }\end{array}$ & $\begin{array}{c}\text { Group II: Delayed } \\
\text { closure (N=20) }\end{array}$ & X2 & p-value \\
\hline Skin irritation & $1(5.0 \%)$ & $8(40.0 \%)$ & 5.161 & 0.023 \\
\hline Parastomal infection & $1(5.0 \%)$ & $0(0.0 \%)$ & 0.095 & 0.733 \\
\hline Leakage outside appliance bag & $3(15.0 \%)$ & $6(30.0 \%)$ & 3.275 & 0.034 \\
\hline High volume output & $3(15.0 \%)$ & $4(20.0 \%)$ & 0.195 & 0.374 \\
\hline Parastomal hernia & $0(0.0 \%)$ & $1(5.0 \%)$ & 0.095 & 0.733 \\
\hline Stenosis & $1(5.0 \%)$ & $1(5.0 \%)$ & 0.000 & 1.00 \\
\hline Prolapse & $0(0.0 \%)$ & $1(5.0 \%)$ & 0.095 & 0.733 \\
\hline Retraction & $1(5.0 \%)$ & $0(0.0 \%)$ & 0.095 & 0.733 \\
\hline Other & $1(5.0 \%)$ & $0(0.0 \%)$ & 0.095 & 0.733 \\
\hline
\end{tabular}

QoL between both groups was compared using modified EORTC questionnaire. None of the patients in the study had symptom scores ranging between 9 and 15 (not improved). Three $(15 \%)$ patients in delayed closure group had symptom scores between 16 and 25 (improved) in contrast to none of them in early closure group. All (100\%) patients in early closure group and $17(85 \%)$ patients in delayed closure group had scores between 26 and 36 (considerably improved). The difference between the two groups were statistically significant, with a $P$ value of 0.027 .

Regarding the cost, there was a significant difference between the two study groups. Earlyclosure group was associated with significantly lower cost than the delayed-closure group $(P$ value $<0.001$ ).

\section{Discussion}

This study provides evidence of the safety, efficacy, and feasibility of early closure of a temporary stoma in selected patients with 
colorectal cancer with a follow up of six months after operation. Only patients assessed for clinically relevant complications related to the index surgery and who were found appropriately fit were invited to enter the study. Therefore, only patients not showing clinical or radiological signs of adverse events after the rectal cancer operation were included and randomized.

We found a significant difference between the two groups regarding our primary endpoint, which was the mean number of complications within 12 months of index surgery. Further, patients in the intervention group had fewer complications than patients in the control group during the follow up. The total number of complications differed significantly over time between groups. In the study by Alves et al, patients had an overall morbidity of $31 \%$ in the early closure group and $38 \%$ in the late closure group at 90 days after stoma creation, which was similar to our results ${ }^{[23]}$. However, they did not report overall complications later in the follow-up period.

Patients included in this study were comparable with regard to baseline characteristics. The adjusted analysis showed similar results with no impact of sex, age, BMI, comorbidity.

Data on surgical closure of the loop ileostomy did not differ between the groups, although 3 patients in the intervention group and 4 patients in the control group experienced complications and some of them had more than one complication. Our results indicated that early closure of a temporary ileostomy is safe, as has been suggested by a previous study ${ }^{[24]}$. The rate of overall complications reported from other studies was higher ${ }^{[23,25,26]}$ and one possible explanation could be criteria for inclusion and exclusion in our trial.

We found a significant difference in the mean number of stoma related complications, in particular relieving patients in the intervention group from skin irritation, Leakage outside appliance bag, and problems urinary tract infection and wound infection. Although stoma related complications may seem less severe than complications, these complications can be tiresome, distressing, and embarrassing for the patient ${ }^{[27,28]}$.
Many patients have their loop ileostomy considerably longer than the suggested 12 weeks, which also could be seen in our study where median time until closure in the control group was 148 days (equivalent to 5 months). Other studies have pointed out that $20 \%$ of the temporary ileostomies were never closed, [29] but only 1 patients $(5 \%)$ in our trial did not undergo closure within the follow-up period of 12 months after index surgery. This patient did eventually undergo reversal of the loop ileostomy, although later than 12 months after index surgery. Previous reports have suggested reasons for non-closure as old age, surgical complications, and comorbidity ${ }^{[30]}$. Possible explanations for the high closure rate $<12$ months in our trial most likely include focus on closure of the ileostomy in the trial setting.

Although it is expected that the delayed closure group stay more in the hospital than the earlyclosure group, the result of our study showed no statistically significant difference between them.

\section{Conclusion}

It could be concluded that in selected patients without clinical, radiological, or endoscopic signs of a leakage early closure of the temporary ileostomy after surgery for colorectal cancer resulted in a significantly lower mean number of complications and lower cost compared with delayed closure. Furthermore, the quality of life was better with the early closure than the delayed closure. We also found low numbers of severe complications in both groups suggesting that patients should be considered for early closure of an ileostomy if they have no signs of anastomotic leakage in the postoperative period after colorectal resection.

\section{References}

1. Matthiessen P, Hallböök $O$, Rutegård J, Sjödahl R. (2006): Population-based study of risk factors for postoperative death after anterior resection of the rectum. $\mathrm{Br} J$ Surg.,93:498-503.

2. Tan WS, Tang CL, Shi L, Eu KW (2009): Meta-analysis of defunctioning stomas in low anterior resection for rectal cancer. $\mathrm{Br} J$ Surg.,96:462-72. 
3. Gastinger I, Marusch F, Steinert R, Wolff S, Koeckerling F, Lippert $\mathrm{H}$ et al. (2005): Protective defunctioning stoma in low anterior resection for rectal carcinoma. $\mathrm{Br} \mathrm{J}$ Surg .92:1137-42.

4. Hüser N, Michalski CW, Erkan M, Schuster T, Rosenberg R, Kleeff $\mathbf{J}$ et al. (2008): Systematic review and meta-analysis of the role of defunctioning stoma in low rectal cancer surgery. Ann Surg.,248:52-60.

5. Montedori A, Cirocchi R, Farinella E, Sciannameo F, Abraha I (2010): Covering ileo- or colostomy in anterior resection for rectal carcinoma. https://www.semanticscholar.org/../Coveringileo-or-colostomy-in-anterior-resection-M...

6. Mattheisen $P$, Hallböök $O$, Rutegård $J$, Simert G, Sjodahl R(2007): Defunctioning stoma reduces symptomatic anastomotic leakage after low anterior resection of the rectum for cancer: A randomized multicenter trial. Ann Surg.,246:207-14.

7. Gooszen AW, Geerlkerken RH, Hermans J, Lagaay MB, Gooszen HG (2000): Quality of life with a temporary stoma: Ileostomy vs. colostomy. Dis Colon Rectum,43:650-5.

8. O'Leary DP, Fide CJ, Foy C, Lucarotti ME (2001): Quality of life after low anterior resection with total mesorectal excision and temporary loop ileostomy for rectal carcinoma. Br J Surg.,88:1216-20.

9. Mala T, Nesbakken A (2008): Morbidity related to the use of a protective stoma in anterior resection for rectal cancer. Colorectal Dis., 10:785-8.

10. Rathnayake MM, Kumarage SK, Wijesuriya SR, Munasinghe BN, Ariyaratne MH, Deen KI (2008): Complications of loop ileostomy and ileostomy closure and their implications for extended enterostomal therapy: A prospective clinical study. Int J Nurs Stud.,45:1118-21.

11. Giannakopoulos GF, Veenhof AA, van der Peet DL, Sietses C, Meijerink WJ, Cuesta MA (2009): Morbidity and complications of protective loop ileostomy. Colorectal Dis., 11:609-12.

12. Poon JT, Law WL, Chu KW (2004): Small bowel obstruction following low anterior resection: The impact of diversion ileostomy. Langenbecks Arch Surg.,389:250-5.

13. Sprangers MA, Taal BG, Aaronson NK, teVelde A (1995): Quality of life in colorectal cancer. Stoma vs. nonstoma patients. Dis Colon Rectum,38:361-9.

14. Silva MA, Ratnayake G, Deen KI (2003): Quality of life of stoma patients: Temporary ileostomy versus colostomy. World $\mathbf{J}$ Surg.,27:421-4.

15. Alves A, Panis Y, Lelong B, Dousset B, Benoist S, Vicaut E (2008): Randomized clinical trial of early versus delayed temporary stoma closure after proctectomy. $\mathrm{Br} \quad \mathbf{J}$ Surg.,95:693-8.

16. Hindenburg $\mathbf{T}$, Rosenberg $\mathbf{J}$ (2010):Closing a temporary ileostomy within two weeks. Dan Med Bull .,57:1-5.

17. Ullah A, Arif A, Khan MA, Nawaz H, Imran A (2013): Frequency of surgical site infection following intestinal stoma closure. Khyber J Med Sci.,6:102-7.

18. Krand O, Yalti T, Berber I, Tellioglu G (2008): Early vs. delayed closure of temporary covering ileostomy: A prospective study.Hepatogastroenterol.,55:142-5.

19. Chow A, Tilney HS, Parasveka P, Jeyarajah S, Zacharakis E, Purkayastha S (2009): The morbidity surrounding reversal of defunctioning ileostomies: A systematic review of 48 studies including 6,107 cases. Int J Colorectal Dis.,24:711-23.

20. Chang MZ, Tsai CC, Hung GU, Lin WY (2000):Tc-99m (V)-DMSA in wound infection after closure of an ileostomy. AnnNucl Med.,19:733-6.

21. Velmahos GC, Degiannis E, Wells M, Souter I, Saadia R (1995): Early closure of colostomies in trauma patients--a prospective randomized trial. Surgery,118:815-20.

22. Robertson JP, Puckett J, Vather R, Jaung R, Bissett I (2015): Early closure of temporary loop ileostomies: A systematic review. Ostomy Wound Manag.,61:50-7.

23. Alves A,Panis Y,Lelong $B$ et al. (2008):Randomized clinical trial of early versus delayed temporary stoma closure after proctectomy. Br J Surg.,95:693-698.

24. Chow A, Tilney HS, Paraskeva $P$ et al. (2009): The morbidity surrounding reversal ofdefunctioning ileostomies: a systematic review of 48 studies including 6107 cases. Int J Colorectal Dis.,24:711-723.

25. Luglio G, Pendlimari R, Holubar SD et al. (2011): Loop ileostomy reversal after colon and rectal surgery: a single institutional 5-year experience in 944 patients. Arch Surg.,146:1191-1196. 
26. vanWestreenen HL, Visser A, Tanis PJ et al. (2012): Morbidity related to defunctioning ileostomy closure after ileal pouch-anal anastomosis and low colonic anastomosis. Int $\mathbf{J}$ Colorectal Dis.,27:49-54.

27. Robertson I, Leung E, Hughes D et al. (2005): Prospective analysis of stoma-related complications. Color Dis., 7:279-285.

28. Sun V, Grant M, McMullen CK et al. (2013): Surviving colorectal cancer: long-term, persistent ostomy-specific concerns and adaptations. J Wound Ostomy Continence Nurs.,40:61-72.

29. David GG, Slavin JP, Willmott $S$ et al. (2010): Loop ileostomy following anterior resection: is it really temporary? Color Dis.,12:428-432.

30. den Dulk M, Smit M, Peeters K et al. (2007): A multivariate analysis of limiting factors for stoma reversal in patients with rectal cancer entered into the total mesorectal excision (TME) trial: a retrospective study. Lancet Oncol.,8:297-303. 